\title{
Early nutrition transition in Haiti: linking food purchasing and availability to overweight status in school-aged children
}

\author{
Alexandra B Morshed ', Haley V Becker ${ }^{1}$, Jacques Raymond Delnatus ${ }^{2}$, Patricia B Wolff ${ }^{2}$ \\ and Lora L lannotti ${ }^{1, *}$ \\ 'Brown School, Washington University in St. Louis, Campus Box 1196, 1 Brookings Drive, St. Louis, \\ MO 63130-4899, USA: ${ }^{2}$ Meds \& Food for Kids, St. Lovis, MO, USA
}

Submitted 11 September 2015: Final revision received 21 April 2016: Accepted 24 May 2016: First published online 4 July 2016

\begin{abstract}
Objective: The primary aim was to examine the association of socio-economic factors and diet with overweight (including obesity) among school-aged children in Haiti. The secondary aim was to describe food availability and the physical activity built environment in participating schools.

Design: This cross-sectional study examined baseline data from the intervention Mamba study assessing the effectiveness of a fortified peanut butter paste in school-aged children. Logistic regression modelling was used to test hypothesized factors in association with overweight status.

Setting: Six primary schools in Cap-Haitien, the second largest city in Haiti.

Subjects: Children ( $n$ 968) aged 3-13 years, in good health and enrolled in a participating school for the 2012/13 school year.

Results: Child age (adjusted OR (AOR); $95 \% \mathrm{CI}=0 \cdot 25 ; 0 \cdot 12,0 \cdot 56$ ), child age squared (1.08; 1.03, 1.13), always purchasing food at school $(3 \cdot 52 ; 1 \cdot 12,11 \cdot 08)$, mother's BMI $(1 \cdot 10 ; 1 \cdot 04,1 \cdot 16)$ and household ownership of a bicycle $(0 \cdot 28 ; 0 \cdot 11,0.71)$ were significantly associated with overweight (likelihood ratio $=36, P<0 \cdot 0001$ ). Consumption of fish was significantly lower in overweight children in the binary analysis $(P=0.033)$ and improved the fit of the model. Schools had limited time and space for physical activity and foods sold by vendors were predominantly high in sugar or fat. Conclusions: To our knowledge the present study is the first to examine the covariates of childhood overweight or describe school food availability and physical activity built environments in Haiti. Further research is necessary to identify intervention targets and feasible, cost-effective approaches for prevention of obesity in Haiti children.
\end{abstract}

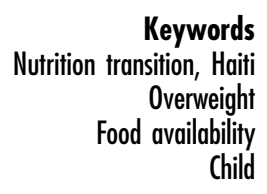

Nutrient deficiencies and stunting are among the primary childhood health concerns in developing countries ${ }^{(1)}$. As low- and middle-income countries undergo the nutrition transition, these populations experience increases in overweight, obesity and associated non-communicable disease simultaneously with persistent undernutrition. Children are among the most vulnerable to the dual burden of malnutrition. Efforts to prevent this emerging epidemic in the early stages are critical.

The nutrition transition is defined as a shift from high prevalence of undernutrition and its related health consequences to increasing predominance of diet-related non-communicable disease ${ }^{(2,3)}$. Nutrition transition and related increases in the prevalence of obesity are largely driven by rapid urbanization and globalization processes that result from technology distribution, transportation, marketing, mass media, and flow of capital and services ${ }^{(4)}$. Although these changes bring about benefits, such as improved food access, they also result in an abundance of inexpensive, processed, high-energy and high-sodium items in the countries' food environments, as well as increased sedentary time, which lead to rises in obesity ${ }^{(4)}$. Childhood obesity is a serious public health problem which tracks into adulthood and leads to increased morbidity and mortality later in life ${ }^{(5-8)}$, with increased risk faced by children who experience early undernutrition followed by rapid weight gain in childhood or adolescence ${ }^{(9)}$. Globally, obesity has more than doubled in the last 35 years ${ }^{(10,11)}$. Among schoolaged children (5-19 years) in low- and middle-income countries, the global prevalence of overweight and obesity is $10 \%$, but varies widely between countries depending on their stage in the nutrition transition ${ }^{(12)}$.

Haiti is a country at an early stage of nutrition transition. It has experienced gross domestic product increases following the disruption from the 2010 earthquake $^{(13)}$, increased urbanization, increased vaccination rates, and 
decreases in child undernutrition and morbidity ${ }^{(14,15)}$. Haiti is also experiencing an increasing prevalence of overweight and obesity among women, particularly in urban areas and higher socio-economic status groups ${ }^{(14,15)}$, and decreasing national supply of fruits and vegetables ${ }^{(16)}$. Haiti's agestandardized overweight prevalence in children $(7.7 \%$ of boys, $9.5 \%$ of girls) is still well below the average for the Caribbean region (13.4\% of boys, $19.9 \%$ of girls) and the prevalence in other culturally and economically similar countries, such as the Dominican Republic, Cuba and Brazil $^{(17)}$. In fact, Haiti's childhood overweight prevalence is closer to the 1980 estimate for the world's developing countries ( $8.1 \%$ of boys, $8.4 \%$ of girls), indicating that Haiti is just at the beginning of the nutrition transition ${ }^{(17)}$.

Predictors of childhood obesity are well characterized. These include high consumption of energy-dense foods and low consumption of fibre, fruits and vegetables, and other nutrient-rich foods; decreased physical activity; and obesogenic food and physical activity environments ${ }^{(12,18-21)}$. However, in the developing world, most nutrition transition research has been carried out in countries that are experiencing higher obesity rates (e.g. India, Mexico, South Africa) than the rest of the lowand middle-income countries ${ }^{(4)}$. This dearth of research in early transitioning countries means that there is a missed opportunity for prevention of the rise in childhood obesity associated with nutrition transition. Haiti is a novel setting for characterization of factors associated with obesity, which would inform the initiation and study of efforts to adapt and implement evidence-based obesity prevention interventions, with the aim of disrupting the negative consequences of the nutrition transition. We hypothesize that, being early in the nutrition transition, overweight and obesity in Haiti will be associated with a higher consumption of processed and high-energy foods (e.g. animal fat); lower consumption of fruits, vegetables and other sources of fibre; and higher socio-economic status $^{(22)}$.

From 2012 to 2013, the Mamba School Feeding study (the Mamba study) was carried out among school-aged children in Cap-Haitien, Haiti, to examine the effects of a fortified snack on nutrition outcomes. The present study used baseline data of that study to accomplish two aims. The primary aim was to examine the association of socio-economic factors and diet with overweight (including obesity) in this population. In order to begin to contextualize the school environment, the present study's secondary aim was to describe food availability and the physical activity built environment in the participating schools.

\section{Methods}

\section{Design and study participants}

The sample was comprised of the Mamba study baseline data. The design and methods of the Mamba study have previously been described in detail ${ }^{(23)}$. Briefly, the study was a group-randomized controlled trial carried out in six primary schools in Cap-Haitien, the second largest city in Haiti, during the 2012/13 school year. Two schools were assigned to each of three conditions: (i) fortified food provided as part of the school's feeding programme; (ii) unfortified food provided as part of the school's feeding programme; and (iii) no snack provided (comparison group). Children were included in the study if they: (i) were 3-13 years old; (ii) had no siblings enrolled in the study; (iii) were in good health (e.g. absence of fever, congenital health condition); (iv) were not severely malnourished (i.e. weight-for-height $Z$-score less than -2); (v) did not have a peanut or soya allergy; and (iv) were enrolled in a participating school for the 2012/13 school year.

Contacts were made with all families of eligible children, and parents or non-parent caregivers of all but two eligible children agreed to participate. Written informed consent was obtained from parents or nonparent caregivers of the children in French and Creole, and verbal assent was obtained from children. Longitudinal measures were taken at baseline (December 2012 to January 2013), midline (March 2013) and endline (June 2013). Children were assessed for weight and height, blood $\mathrm{Hb}$ concentration, body composition via bioelectrical impedance, educational outcomes and acceptability of the school snack if given. Additional information regarding socio-economic and demographic characteristics, child diet and health, and parent anthropometry was collected from children's parents or non-parent caregivers.

The present study used the baseline data from the Mamba study ( $n$ 1084), because these data were not influenced by the Mamba intervention. After children with missing values for BMI were removed, data on 968 participants remained and were used in the analysis.

\section{Measures}

Anthropometric measures of the children and caregivers were performed by trained study personnel ${ }^{(23)}$. Weight was measured to the nearest $0 \cdot 1 \mathrm{~kg}$ using a Seca model 874 (digital) scale $(440 \mathrm{lb} \times 0 \cdot 1 \mathrm{lb}$ resolution $(\sim 200 \mathrm{~kg} \times \sim 45 \mathrm{~g}$ resolution)). Height was measured to the nearest $1 \mathrm{~mm}$ using the ShorrBoard measuring board. For children's height and weight, two independent measures were taken, with a third measure taken if the difference between the first measures was outside the acceptable range. The averages of the height and weight measures were used to calculate BMI $Z$-scores using the WHO Growth Standards for children 3-5 years of age ${ }^{(24)}$ and WHO Growth References for children $6-13$ years of age ${ }^{(25)}$. Child overweight was defined as BMI $Z$-score greater than +1 and includes obese children. A dichotomous variable for child overweight $(0=$ normal or underweight, $1=$ overweight or obese) was used in analyses.

Dietary, child morbidity, socio-economic and demographic variables were assessed using the caregiver 
interview. Children's dietary intake was assessed using the $24 \mathrm{~h}$ FFQ from the Demographic and Health Surveys Program that is used to measure dietary intake in lowand middle-income countries around the world ${ }^{(26)}$. The questionnaire was adapted to the Haiti context based on formative research to reflect foods commonly consumed by the target population. Caregivers were asked how many times the child ate the following food items in the previous $24 \mathrm{~h}$ : bread; cereals, porridge or other grains; roots and tubers; beans and other legumes; eggs; milk; fermented milk or yoghurt; cheese and other dairy products; poultry; other meat; fish and shellfish; fruits; vegetables; oils, butter and other fats; crackers; and cookies.

These food items were also combined into food groups based on their energy and nutrient density ${ }^{(27)}$ and standardly applied food categories: fruits and vegetables; meat, fish, dairy and eggs; processed foods; and starchy foods. In addition, two approaches were used to characterize other aspects of the diet. First, the dietary diversity score $^{(28)}$ was calculated to represent overall diet quality. Second, dietary patterns were derived using principal components analysis by grouping food items to reflect patterns of dietary intake.

To measure food purchasing at school, caregivers were asked how often the child buys a snack or lunch at school, with the possible answer options being 'always', 'sometimes' or 'never'. Other measures of socio-economic status included mother's education level (years), household monthly income (100-500, 501-800, 801-1000, 1001+ Haitian dollars), amount the household spent on food yesterday (0-20, 21-40, 41-60, 60+ Haitian dollars), whether the household receives remittances (yes, no), number of people living in the household, frequency of electricity availability in the home (always, sometimes, never), whether the household has a flush toilet (yes, no) and whether the household shares a toilet with other households (yes, no).

Child age, morbidity, micronutrient supplementation and mother's BMI were captured and used as potential covariates. Child age (years) was measured at baseline using the child's birthday and the date of survey administration. Caregivers were asked to recall whether the child had diarrhoea or fever in the past 2 weeks and whether the child had received vitamin A supplementation or deworming tablets in the past 6 months. Mother's BMI was measured by trained study personnel using research grade equipment. Averages of independent measures of height and weight were used to calculate BMI, defined as weight divided by height squared.

To examine food availability and the physical activity built environment in participating schools, structured observations and interviews with school personnel were carried out. School personnel provided information regarding school policy for the length of physical activity and recreation time $(\mathrm{min} / \mathrm{d})$. The size $\left(\mathrm{m}^{2}\right)$ and density $\left(\mathrm{m}^{2} /\right.$ student) of the outdoor space and availability of shade and green space (yes, no) were collected through direct observation and measurement of school grounds. Study team members collected exact measures of the dimensions of outdoor space at each school. These measures were then converted to density by dividing by the total student population. Food availability was defined as the presence of foods obtainable from food vendors on school grounds or in the immediate area. Study personnel carried out an inventory of food items being sold at each school. In addition, school hours of operation and the presence of electricity, latrines and water pumps were collected as descriptive characteristics of the schools.

\section{Data analysis}

Differences in participant characteristics and dietary intake between overweight (including obese) and nonoverweight children were examined using Pearson's $\chi^{2}$ and Fisher's exact test for categorical variables, and the Wilcoxon rank sum test for continuous variables, as these were not normally distributed.

Logistic regression was used to examine the association between potential predictors of overweight and child overweight status. Potential predictors of overweight were entered into the model as follows, and they were retained if they significantly predicted overweight or improved model fit based on the Akaike information criterion and $-2 \log$ likelihood statistics, while retaining model quality. Child age and sex were entered into the model first. As the relationship between child age and the dependent variable was not linear, a polynomial term for age (age squared) was added to improve model fit. Socio-economic status variables were entered next, followed by child health variables (i.e. diarrhoea or fever morbidities, vitamin A supplementation and deworming), dietary intake variables and finally mother's BMI. In each model, the Hosmer-Lemeshow test and the $c$ statistic were used to evaluate the quality of the model (whether the model was significantly different from the data) ${ }^{(29)}$. Multicollinearity was examined using variance inflation factors ${ }^{(30)}$. The final model included: the constant, child's sex, child's age, child's age squared, whether child purchases food at school, whether the household owns a bicycle, child's consumption of meat (excluding fish), child's consumption of dairy and eggs, child's consumption of fish and mother's BMI. Odds ratios of overweight across predictor levels and their confidence intervals were calculated to examine the association.

As a sensitivity analysis, dietary patterns were derived and along with the dietary diversity score considered for inclusion in the logistic regression models to examine the association of overall diet with child overweight. The dietary patterns were derived using principal components analysis using previously described methods ${ }^{(31)}$. Six dietary patterns were extracted based on the eigenvalue greater than 1 cut-off point, and two dietary patterns were extracted using the scree test. The patterns were rotated 
using the orthogonal Varimax rotation method, which loads the food items maximally on to one dietary pattern while keeping the patterns independent, thus improving interpretability ${ }^{(32)}$. The dietary diversity score and dietary patterns were included in the logistic regression modelbuilding described above, but none were significantly predictive of overweight independently of individual food groups, nor did they improve the model fit. Therefore, they were not included in the final model.

All analyses were conducted using the statistical software package SAS version 9.4.

\section{Results}

\section{Study characteristics}

Overweight children (including obese) and nonoverweight children did not differ statistically by child characteristics (Table 1). Mothers of overweight children showed a significantly higher BMI than mothers of non-overweight children. As well, a significantly lower proportion of overweight child households shared a toilet with other households than did non-overweight child households. Other maternal and household health and socio-economic characteristics did not differ by group.

The prevalence of children who were overweight or obese was $5.1 \%$ in the present study. Obesity-only prevalence was $1.8 \%$. Similar prevalence of overweight was observed among girls (5.6\%) and boys (4.5\%). Significant differences in overweight, however, were observed by age group with the youngest ( $3-5$ years old) and oldest (12-13 years old) children experiencing higher overweight rates than the other children.

\section{Bivariate analysis of dietary intake}

Few significant differences were observed in bivariate analyses of individual food items and food groups by overweight status. The overweight children had a significantly lower $(-0 \cdot 11)$ mean frequency of fish intake than non-overweight children (data not shown).

\section{Association between child overweight and socio- economic and diet factors}

The final logistic regression model of overweight status (Table 2) satisfied the convergence criteria and was significant (likelihood ratio $(\mathrm{df}=10)=36, \quad P<0 \cdot 0001)$. The Hosmer and Lemeshow goodness-of-fit statistic ( $H-L$ $(\mathrm{df}=8, n 778)=7 \cdot 70, P=0.463)$ and the $c$ statistic $(0 \cdot 721)$ indicated acceptable quality of the model.

Child age, child age squared, always purchasing food at school (compared with never), household ownership of a bicycle and mother's BMI were significantly associated with child overweight. The protective effect of child age and negative effect of child age squared on child overweight indicated that when children are in their early years, they are less likely to be overweight as they age; however in later years, the risk of overweight increases with increasing age, which suggests a curvilinear relationship between overweight and age. Children who always purchase food at school experienced significantly increased odds of being overweight than children who never purchase food at school. For every one point increase in maternal BMI, the risk of child overweight increased by $10 \%$. Children whose household owned a bicycle faced reduced odds of overweight by $82 \%$ compared with children whose household did not own a bicycle.

Sex of the child and consumption of meat, fish, and dairy and eggs were retained in the model as they improved model fit based on the Akaike information criterion or $-2 \log$ likelihood statistics.

None of the measures of overall diet quality (i.e. dietary diversity score or dietary patterns) were significantly associated with overweight independently of individual food groups, nor did they improve the model fit. Therefore, they were not included in the final model.

\section{School environment}

Schools were ordered first by type (private then public) and then within these categories by size of the total student population (Table 3). Hours of operation and the proportion of recreation time were comparable across all six schools. Of the $5 \mathrm{~h}$ school day, 5-7\% was devoted to recreation or physical activity time. Overall, there was limited outdoor recreational space, and only two schools had shade or green space. No evident relationship between percentage overweight and outdoor space density was found, although the private schools were among the schools with higher proportions of overweight and lower outdoor space density. Across all six schools, only one had a water pump and electricity.

All six schools had food vendors on the school property or in the immediate surrounding area; although School 3, a small public periurban school, had only one small kiosk with a limited selection of foods. The vendors sold processed foods (chips, cookies, crackers, ice cream, popcorn, sweets and sweet starch), fried foods (banana, dough, horse meat, hot dog), prepared foods (bread with peanut butter, hard-boiled eggs, boiled manioc, rice and beans/peas, sweet potatoes with milk, roasted peanuts), fruit (bananas and mangos), frozen fruit juice, sugarsweetened beverages (fruit drinks, shaved ice with syrup) and coffee.

\section{Discussion}

Overweight was significantly associated with child age, always purchasing food at school, mother's BMI and household ownership of a bicycle. The assessment of food availability and the physical activity environment at schools revealed limited time and space for physical activity, and high availability of unhealthy food options for 
Table 1 Socio-economic and demographic characteristics by overweight status among children ( $n$ 968) from six primary schools in Cap-Haitien, Haiti, 2012/13 school year

\begin{tabular}{|c|c|c|c|c|c|}
\hline & \multicolumn{2}{|c|}{ Non-overweight† (n 919) } & \multicolumn{2}{|c|}{ Overweight $\ddagger$ ( $n$ 49) } & \multirow[b]{2}{*}{$P$ value } \\
\hline & $\%$ or mean & SD & $\%$ or mean & SD & \\
\hline \multicolumn{6}{|l|}{ Child characteristics } \\
\hline Child age & & & & & 0.001 \\
\hline $3-5$ years $(\%)$ & $15 \cdot 2$ & - & $28 \cdot 6$ & - & \\
\hline $6-8$ years $(\%)$ & 37.5 & - & 22.5 & - & \\
\hline $9-11$ years $(\%)$ & $36 \cdot 8$ & - & $26 \cdot 5$ & - & \\
\hline $12-13$ years $(\%)$ & $10 \cdot 5$ & _- & 22.4 & - & \\
\hline Child female (\%) & $51 \cdot 8$ & - & $57 \cdot 1$ & - & 0.558 \\
\hline Received vitamin A supplementation in past 6 months (\%) & 18.9 & _ & 24.5 & _- & 0.352 \\
\hline Took deworming tablets in past 6 months (\%) & $76 \cdot 1$ & - & 83.7 & - & 0.299 \\
\hline Had diarrhoea in past 2 weeks $(\%)$ & $12 \cdot 4$ & - & 8.2 & - & 0.503 \\
\hline Had a fever in past 2 weeks (\%) & 23.4 & - & $20 \cdot 4$ & - & 0.730 \\
\hline Frequency child buys food at school & & & & & 0.263 \\
\hline Always (\%) & 17.4 & _ & $26 \cdot 5$ & - & \\
\hline Sometimes (\%) & 55.4 & - & $49 \cdot 0$ & - & \\
\hline \multirow{2}{*}{\multicolumn{6}{|c|}{ Mother's characteristics }} \\
\hline & & & & & \\
\hline Mother's BMI $\left(\mathrm{kg} / \mathrm{m}^{2}\right) \S$, mean and SD & $23 \cdot 17$ & 4.59 & $25 \cdot 45$ & $6 \cdot 66$ & 0.026 \\
\hline Mother's education (years) II, mean and SD & 4.51 & 3.51 & 4.02 & 3.57 & 0.403 \\
\hline \multicolumn{6}{|l|}{ Household characteristics } \\
\hline Number of household members, mean and SD & $6 \cdot 43$ & $2 \cdot 68$ & $6 \cdot 49$ & 1.92 & 0.252 \\
\hline Household monthly income (excluding remittances) & & & & & 0.266 \\
\hline \$Haitian 100-500 (\%) & $66 \cdot 3$ & - & $65 \cdot 3$ & - & \\
\hline \$Haitian 501-800 (\%) & $14 \cdot 3$ & - & $20 \cdot 4$ & - & \\
\hline \$Haitian 801-1000 (\%) & 7.7 & - & $10 \cdot 2$ & - & \\
\hline \$Haitian 1001+ (\%) & $11 \cdot 7$ & - & $4 \cdot 1$ & - & \\
\hline Remittances received (\%) & $21 \cdot 0$ & - & 24.5 & - & 0.590 \\
\hline Amount spent on food yesterday & & & & & 0.529 \\
\hline \$Haitian 0-20 (\%) & $32 \cdot 0$ & - & 24.5 & - & \\
\hline \$Haitian 21-40 (\%) & 33.5 & - & $32 \cdot 7$ & - & \\
\hline \$Haitian 41-60 (\%) & $18 \cdot 8$ & - & $20 \cdot 4$ & - & \\
\hline \$Haitian 61+ (\%) & $15 \cdot 7$ & - & $22 \cdot 5$ & - & \\
\hline Number of rooms in the house, mean and SD & 2.42 & 1.58 & 2.22 & $1 \cdot 18$ & 0.808 \\
\hline Frequency of electricity in house & & & & & 0.203 \\
\hline Always (\%) & $7 \cdot 3$ & - & $14 \cdot 3$ & - & \\
\hline Sometimes (\%) & $48 \cdot 8$ & - & 44.9 & - & \\
\hline Never (\%) & 43.9 & - & $40 \cdot 8$ & - & \\
\hline Household has flush toilet (\%) & $7 \cdot 1$ & - & $2 \cdot 0$ & - & 0.247 \\
\hline Household shares toilet with other households (\%) & 39.2 & - & $18 \cdot 4$ & - & 0.004 \\
\hline
\end{tabular}

†Non-overweight is defined as children with a BMI Z-score less than or equal to +1 .

$\neq$ Overweight is defined as children with a BMI Z-score greater than +1 and includes obese children.

$\S 185$ observations are missing from the mother's BMI variable.

॥212 observations are missing from the mother's education variable.

purchase. Recreation time for children ranged from 15 to $20 \mathrm{~min} / \mathrm{d}$, below the Institute of Medicine's recommendation of both 30 min of physical education daily and additional vigorous- or moderate-intensity physical activity throughout the school day ${ }^{(33)}$.

Children who always purchase their lunch at school experienced higher odds of being overweight than children who did not, independent of other socioeconomic exposures. In this relationship, availability of high-fat or high-sugar foods may have played a role, although this was not possible to evaluate in the present study due to the number of participating schools. Several studies from South Africa and Swaziland have documented in detail the poor nutritional quality of vendor foods sold near schools, and in South Africa a positive association was observed between overweight and purchasing of those foods by students ${ }^{(34-37)}$. The positive relationship between purchasing power and overweight observed in the present study is also consistent with past findings that the relationship between obesity and socioeconomic status is modified by the country's economic development level ${ }^{(38)}$, given that Haiti is one of the lower-income countries in Latin America.

A country that is transitioning to higher prevalence of chronic disease has a typical dietary profile characterized by higher consumption of fat, sugar and processed foods, and lower consumption of fibre, fruits and vegetables, although the specific dietary patterns are variable within and between countries ${ }^{(11,17-19)}$. Despite not reaching significance in the present study, inclusion of consumption of meat, fish, and dairy and eggs improved model fit and may indicate a possible role for these foods in overweight or obesity interventions. Eggs have previously been identified as a cost-effective and often overlooked 
component of maternal and young child nutrition, and their potential role in prevention of overweight is encouraging $^{(39)}$. Dietary patterns that include foods high in monounsaturated and polyunsaturated fats (such as fish) are associated with prevention and reduction in chronic disease ${ }^{(40)}$.

A large body of evidence exists for what is effective in prevention of obesity in school-aged children ${ }^{(41-44)}$, although few of the effectiveness studies have been conducted in Latin America ${ }^{(45,46)}$, and little is available from sub-Saharan Africa and particularly countries like Benin, Ghana and Congo which have similar epidemiological trends to Haiti ${ }^{(47,48)}$. School-based interventions have been favoured in the past most likely because children spend a large amount of their time at school, school

Table 2 Logistic regression model† predicting overweight statusł among children $(n$ 778) from six primary schools in Cap-Haitien, Haiti, 2012/13 school year

\begin{tabular}{|c|c|c|}
\hline Model parameter & OR & $95 \% \mathrm{Cl}$ \\
\hline Male & 0.62 & $0.31,1.24$ \\
\hline Child age (years) & 0.25 & $0.12,0.56^{\star \star \star}$ \\
\hline Child age squared $\left(\right.$ years $^{2}$ ) & 1.08 & $1.03,1.13^{\star \star \star}$ \\
\hline \multicolumn{3}{|l|}{ Child purchases food at school } \\
\hline Always & 3.52 & $1.12,11.08^{*}$ \\
\hline Sometimes & 1.59 & $0.57,4.43$ \\
\hline $\begin{array}{l}\text { Frequency of child's consumption of } \\
\text { meat (excluding fish) }\end{array}$ & $1 \cdot 31$ & $0.74,2 \cdot 31$ \\
\hline Frequency of child's consumption of fish & 0.32 & $0.05,2.27$ \\
\hline $\begin{array}{l}\text { Frequency of child's consumption } \\
\text { of dairy and eggs }\end{array}$ & 0.55 & $0 \cdot 28,1 \cdot 10$ \\
\hline Mother's BMI & $1 \cdot 10$ & $1.04,1 \cdot 16^{\star \star}$ \\
\hline Household owns a bicycle & 0.28 & $0.11,0.71^{* *}$ \\
\hline
\end{tabular}

${ }^{\star} P<0.05,{ }^{\star \star} P<0.01,{ }^{\star \star \star} P<0.001$.

†The overall model satisfies convergence criteria and is significant (likelihood ratio $(\mathrm{df}=10)=36, \quad P<0.0001)$. The Hosmer and Lemeshow goodness-of-fit statistic $(H-L(\mathrm{df}=8, n 778)=7.70, P=0.463)$ and the $c$ statistic at 0.721 are both acceptable.

¥Overweight is defined as children with a BMI $Z$-score greater than +1 and includes obese children. settings inherently expose children to dietary and physical activity factors, and schools allow for institutionalization and sustainment of interventions ${ }^{(42)}$. Strong evidence exists for high-intensity, comprehensive and multicomponent interventions, which often include a nutrition and physical activity curriculum, a family component and a healthy food environment, although information regarding cost of these interventions is absent ${ }^{(41-43)}$. Evidence of effectiveness in Latin America is mostly comprised of interventions that included in-school nutrition and physical education classes and were carried out in Mexico, Chile and Brazil ${ }^{(45,49)}$.

Limited evidence exists for policy and environmental strategies for prevention of childhood obesity ${ }^{(42,44)}$, even though these tend to be more affordable and sustainable than promoting individual behavioural changes ${ }^{(21)}$. School nutrition guidelines and reduced pricing for healthy foods sold at school have been shown to improve children's dietary intake ${ }^{(50)}$. In addition, a novel method recently used for assessing evidence of effectiveness found that strategies targeting school food, beverage and physical activity policies and environments, food pricing, availability of parks and recreational facilities, and point-of-decision prompts were effective in prevention of childhood obesity $^{(44)}$. As recent governmental obesity prevention policies enacted in Mexico, Brazil and Chile ${ }^{(51)}$ undergo evaluation in the future, these may serve as examples for what is possible in the Haiti context.

\section{Study limitations}

We were able to draw on multiple dietary and socioeconomic data from a large nutrition intervention study to examine an emerging public health nutrition issue in Haiti. However, secondary analysis of existing data potentially presents some limitations. We used baseline data and a cross-sectional analysis, and therefore no conclusions

Table 3 School environment profile and student BMI category in six primary schools in Cap-Haitien, Haiti, 2012/13 school year

\begin{tabular}{|c|c|c|c|c|c|c|}
\hline Characteristic & $\begin{array}{c}\text { School } 1 \\
\text { (private, urban) }\end{array}$ & $\begin{array}{c}\text { School } 2 \\
\text { (private, urban) }\end{array}$ & $\begin{array}{c}\text { School } 3 \\
\text { (public, periurban) }\end{array}$ & $\begin{array}{c}\text { School } 4 \\
\text { (public, urban) }\end{array}$ & $\begin{array}{c}\text { School } 5 \\
\text { (public, periurban) }\end{array}$ & $\begin{array}{c}\text { School } 6 \\
\text { (public, urban) }\end{array}$ \\
\hline Total student population $(n)$ & 280 & 568 & 145 & 213 & 388 & 690 \\
\hline Study participants $(n)$ & 159 & 299 & 109 & 87 & 255 & 258 \\
\hline \multicolumn{7}{|l|}{ Student BMI } \\
\hline BMI Z-score & -0.65 & -0.51 & $-1 \cdot 20$ & -0.80 & -0.64 & -0.69 \\
\hline SD & 0.95 & 1.04 & 0.88 & 0.95 & $1 \cdot 23$ & 0.92 \\
\hline BMI $\left(\mathrm{kg} / \mathrm{m}^{2}\right)$ & 14.86 & $15 \cdot 53$ & $14 \cdot 37$ & $15 \cdot 67$ & $15 \cdot 78$ & 14.83 \\
\hline $\mathrm{SD}$ & $1 \cdot 33$ & 2.05 & $1 \cdot 14$ & $1 \cdot 86$ & 3.54 & $1 \cdot 34$ \\
\hline Overweight (\%)† & $5 \cdot 4$ & $6 \cdot 4$ & $1 \cdot 1$ & $4 \cdot 1$ & $6 \cdot 2$ & $4 \cdot 3$ \\
\hline \multicolumn{7}{|l|}{ School recreation and facilities } \\
\hline Recreation time (min) & 20 & 20 & $15-20$ & $15-20$ & $15-20$ & 20 \\
\hline Outdoor space area $\left(\mathrm{m}^{2}\right)$ & 110 & 258 & 87 & - & 1750 & 2850 \\
\hline $\begin{array}{l}\text { Outdoor space density } \\
\left.\text { ( } \mathrm{m}^{2} / \text { student }\right)\end{array}$ & 0.4 & 0.5 & 0.6 & - & 4.5 & $4 \cdot 1$ \\
\hline Shade or green space & No & Yes & No & No & No & Yes \\
\hline Latrines $(n)$ & 3 & 3 & 2 & 1 & 3 & 4 \\
\hline Water pump & No & Yes & No & No & No & No \\
\hline Electricity & No & Yes & No & No & No & No \\
\hline
\end{tabular}

†Overweight is defined as children with a BMI Z-score greater than +1 and includes obese children. 
regarding causality can be made. Further, we were not able to examine the full set of factors that could potentially be influencing overweight and obesity in the country. There may also have been limitations arising from assessment of children's dietary intake using a short-recall FFQ, such as daily variation in food intake, selective misreporting of results, caregiver recall bias, absence of sufficient data to calculate total energy intake, and other factors.

\section{Conclusion}

To our knowledge, the present study is the first to examine the covariates of childhood overweight or describe food availability and the physical activity built environment in Haiti schools. The increasing prevalence of overweight among children and adults has been extensively documented in other Latin American countries as they underwent their own nutrition transitions ${ }^{(4,49,52-56)}$. As the public health nutrition programmes of Haiti and similar countries face the new complexities of the dual burden of overweight and undernutrition, there is an opportunity to draw on previous experiences and evidence in order to intervene early and in a targeted manner. The early nutrition transition period is a particularly important time for action, because of the opportunity to prevent the rises in overweight and obesity associated with this phenomenon before they become entrenched. However, limited research from early nutrition transition settings exists. Further studies are needed to adapt and implement effective and cost-effective interventions, such as changes to the food environment, for urban communities in Haiti and other similar contexts. Surveillance of the urban built environments and policies is needed before further increases in overweight prevalence occur. Lessons from Haiti may eventually be applied to other very early transition countries in the future.

\section{Acknowledgements}

Acknowledgements: The authors thank the study participants for generously offering their time; members of the study team; Summer Program for Research in Global Health (SPRINGH) fellow Charmayne Cooley of the Institute for Public Health at Washington University in St. Louis; and Brown School graduate student, Teresa Tufte. Financial support: This research was supported by the US Department of Agriculture (USDA) Foreign Agricultural Service's Micronutrient Fortified Food Aid Products programme (grant number FFE-521-2012/034-00). The USDA Foreign Agricultural Service had no role in the design, analysis or writing of this article. This publication was also supported by Washington University in St. Louis Global Health Center of the Institute for Public Health. Conflict of interest: The authors have no conflict of interest to report. Authorship: L.L.I. and P.B.W. designed and L.L.I., J.R.D. and P.B.W. conducted the Mamba study. A.B.M., H.V.B. and L.L.I. designed the present study. A.B.M. carried out the data analysis. A.B.M., L.L.I. and H.V.B. made analytic decisions and interpreted data. A.B.M., H.V.B. and L.L.I. wrote the manuscript. All authors read and approved the final manuscript. Ethics of buman subject participation: This study was conducted according to the guidelines laid down in the Declaration of Helsinki and all procedures involving human subjects were approved by the National Bioethics Committee of Haiti and the Human Research Protection Office of Washington University in St. Louis. Written informed consent was obtained from all participants.

\section{References}

1. UNICEF, World Health Organization \& World Bank (2015) Levels and trends in child malnutrition. http://www.who.int/ nutrition/publications/jointchildmalnutrition_2015_estimates. pdf?ua=1 (accessed March 2016).

2. Popkin BM (2009) Global changes in diet and activity patterns as drivers of the nutrition transition. Nestle Nutr Workshop Ser Pediatr Program 63, 1-10.

3. Rivera JA, Barquera S, González-Cossío T et al. (2004) Nutrition transition in Mexico and in other Latin American countries. Nutr Rev 62, 7 Pt 2, S149-S157.

4. Popkin B, Adair L \& Ng S (2012) Now and then: the global nutrition transition: the pandemic of obesity in developing countries. Nutr Rev 70, 3-21.

5. Serdula MK, Ivery D, Coates RJ et al. (1993) Do obese children become obese adults? A review of the literature. Prev Med 22, 167-177.

6. Freedman DS, Khan LK, Serdula MK et al. (2005) The relation of childhood BMI to adult adiposity: the Bogalusa Heart Study. Pediatrics 115, 22-27.

7. Reilly JJ \& Kelly J (2010) Long-term impact of overweight and obesity in childhood and adolescence on morbidity and premature mortality in adulthood: systematic review. Int $J$ Obes (Lond) 35, 891-898.

8. Daniels SR (2006) The consequences of childhood overweight and obesity. Future Child 16, 47-67.

9. Victora C, Adair L, Fall C et al. (2008) Maternal and child undernutrition: consequences for adult health and human capital. Lancet 371, 340-357.

10. World Health Organization (2000) Obesity: Preventing and Managing the Global Epidemic. Report of a WHO Consultation. WHO Technical Report Series no. 894. Geneva: WHO.

11. World Health Organization (2015) Obesity and overweight fact sheet. http://www.who.int/mediacentre/factsheets/ fs311/en/\# (accessed September 2015).

12. Gupta N, Goel K, Shah P et al. (2012) Childhood obesity in developing countries: epidemiology, determinants, and pevention. Endocr Rev 33, 48-70.

13. The World Bank (2016) Haiti. http://data.worldbank.org/ country/haiti, (accessed January 2016).

14. Cayemittes M, Busangu MF, Bizimana JD et al. (2013) Enquête Mortalité, Morbidité et Utilisation des Services, Haïti, 2012. Calverton, MD: Ministère de la Santé Publique et de la Population, Institut Haïtien de l'Enfance and Macro International Inc.

15. Cayemittes M, Placide MF, Mariko S et al. (2007) Enquête Mortalité, Morbidité et Utilisation des Services, Haïti, 2005-2006. Calverton, MD: Ministère de la Santé Publique et de la Population, Institut Haitien de l'Enfance and Macro International Inc. 
16. International Food Policy Research Institute (2014) 2014 Nutrition Country Profile - Haiti. http://ebrary.ifpri. org/cdm/ref/collection/p15738coll2/id/128540 (accessed January 2016).

17. Ng M, Fleming T, Robinson M et al. (2014) Global, regional, and national prevalence of overweight and obesity in children and adults during 1980-2013: a systematic analysis for the Global Burden of Disease Study 2013. Lancet 384, 766-781.

18. Popkin BM (2006) Global nutrition dynamics: the world is shifting rapidly toward a diet linked with noncommunicable diseases. Am J Clin Nutr 84, 289-298.

19. Malik VS, Willett WC \& Hu FB (2013) Global obesity: trends, risk factors and policy implications. Nat Rev Endocrinol 9 , 13-27.

20. Drewnowski A \& Popkin B (1997) The nutrition transition: new trends in the global diet. Nutr Rev 55, 31-43.

21. Swinburn BA, Sacks G, Hall KD et al. (2011) The global obesity pandemic: shaped by global drivers and local environments. Lancet 378, 804-814.

22. Popkin BM (1993) Nutritional patterns and transitions. Popul Dev Rev 19, 138-157.

23. Iannotti LL, Henretty NM, Delnatus JR et al. (2015) Ready-touse supplementary food increases fat mass and BMI in Haitian school-aged children. J Nutr 145, 813-822.

24. World Health Organization (2006) The WHO Child Growth Standards. http://www.who.int/childgrowth/en/ (accessed October 2014)

25. World Health Organization (2007) Growth Reference Data for 5-19 Years. http://www.who.int/growthref/en/ (accessed October 2014).

26. Demographic and Health Surveys Program (2016) Questionnaires and Modules. http://www.dhsprogram.com/ What-We-Do/Questionnaires.cfm (accessed January 2016).

27. Drewnowski A (2005) Concept of a nutritious food: toward a nutrient density score. Am J Clin Nutr 82, 721-732.

28. Swindale A \& Bilinsky P (2006) Household Dietary Diversity Score (HDDS) for Measurement of Household Food Access: Indicator Guide. Washington, DC: Food and Nutrition Technical Assistance Project, Academy for Educational Development.

29. Hosmer DW \& Lemeshow S (2000) Applied Logistic Regression, 2nd ed. New York: John Wiley \& Sons.

30. Myers RH (1990) Classical and Modern Regression with Applications vol. 2. Belmont, CA: Duxbury Press.

31. Newby PK \& Tucker KL. (2004) Empirically derived eating patterns using factor or cluster analysis: a review. Nutr Rev 62, 177-203.

32. Field A \& Miles J (2010) Discovering Statistics Using SAS. London: SAGE.

33. Institute of Medicine (2013) Educating the Student Body: Taking Physical Activity and Physical Education to School. Washington, DC: The National Academies Press.

34. Wojcicki JM \& Elwan D (2014) Primary school nutrition and tuck shops in Hhoho, Swaziland. J Child Nutr Manage 38 , issue 1; available at https://schoolnutrition.org/5-Newsand-Publications/4-The-Journal-of-Child-Nutrition-and-Manage ment/Spring-2014/Volume-38,-Issue-1,-Spring-2014—Wojcicki,Elwan/

35. Wiles NL, Green JM \& Veldman FJ (2013) Tuck-shop purchasing practices of Grade 4 learners in Pietermaritzburg and childhood overweight and obesity. South Afr J Clin Nutr 26, 37-42.

36. de Villiers A, Steyn NP, Draper CE et al. (2012) 'HealthKick': formative assessment of the health environment in lowresource primary schools in the Western Cape Province of South Africa. BMC Public Health 12, 794.

37. Wiles NL, Green JM \& Veldman FJ (2011) The variety, popularity and nutritional quality of tuck shop items available for sale to primary school learners in Pietermaritzburg, South Africa. South Afr J Clin Nutr 24, $129-135$.

38. Monteiro CA, Moura EC, Conde WL et al. (2004) Socioeconomic status and obesity in adult populations of developing countries: a review. Bull World Health Organ 82, 940-946.

39. Iannotti LL, Lutter CK, Bunn DA et al. (2014) Eggs: the uncracked potential for improving maternal and young child nutrition among the world's poor. Nutr Rev $\mathbf{7 2}$, 355-368.

40. Willett WC (2012) Nutritional Epidemiology, 3rd ed. Oxford: Oxford University Press.

41. World Health Organization (2009) Interventions on diet and physical activity: what works: summary report. http://www. who.int/iris/handle/10665/44140 (accessed August 2015).

42. Khambalia AZ, Dickinson S, Hardy LL et al. (2012) A synthesis of existing systematic reviews and meta-analyses of school-based behavioural interventions for controlling and preventing obesity. Obes Rev 13, 214-233.

43. Waters E, de Silva Sanigorski A, Hall BJ et al. (2011) Interventions for preventing obesity in children. Cochrane Database Syst Rev issue 12, CD001871.

44. Brennan LK, Brownson RC \& Orleans CT (2014) Childhood obesity policy research and practice: evidence for policy and environmental strategies. Am J Prev Med 46, e1-e16.

45. Lobelo F, Garcia de Quevedo I, Holub CK et al. (2013) School-based programs aimed at the prevention and treatment of obesity: evidence-based interventions for youth in Latin America. I Sch Health 83, 668-677.

46. Holub CK, Elder JP, Arredondo EM et al. (2013) Obesity control in Latin American and US Latinos: a systematic review. Am J Prev Med 44, 529-537.

47. Naidoo R, Coopoo Y, Lambert EV et al. (2009) Impact of a primary school-based nutrition and physical activity intervention on learners in KwaZulu-Natal, South Africa: a pilot study. South Afr I Sports Med 21, 7-12.

48. Draper CE, de Villiers A, Lambert EV et al. (2010) HealthKick: a nutrition and physical activity intervention for primary schools in low-income settings. BMC Public Health 10, 398.

49. Hoehner CM, Soares J, Perez DP et al. (2008) Physical activity interventions in Latin America: a systematic review. Am J Prev Med 34, 224-233.

50. Jaime PC \& Lock K (2009) Do school based food and nutrition policies improve diet and reduce obesity? Prev Med 48, 45-53.

51. Kain J, Cordero SH, Pineda D et al. (2014) Obesity prevention in Latin America. Curr Obes Rep 3, 150-155.

52. Uauy R \& Kain J (2002) The epidemiological transition: need to incorporate obesity prevention into nutrition programmes. Public Health Nutr 5, 223-229.

53. Uauy R \& Vio F (2007) Health and nutrition transition in developing countries: the case of Chile. In The Nation's Nutrition, pp. 117-128 [E Kennedy and R Deckelbaum, editors]. Washington, DC: International Life Sciences Institute.

54. Rivera JA, Rodriguez G, Shamah T et al. (2000) Implementation, monitoring, and evaluation of the nutrition component of the Mexico Social Programme (PROGRESA). Food Nutr Bull 21, 35-42

55. Rivera J, Shamah T, Villalpando S et al. (2005) Effectiveness of an iron fortified milk distribution program in reducing the rates of anemia of infants and young children in Mexico. FASEB J 19, 848.3 (abstr.).

56. Tzioumis E \& Adair L (2014) Childhood dual burden of under- and over nutrition in low- and middle-income countries: a critical review. Food Nutr Bull 35, 230-243. 